Images in

Cardiovascular

Medicine

Syed Asif Masood, MD John W. Bokowski, PhD, RDCS

Suhaib Kazmouz, MD Zahid Amin, MD

\section{Section Editor:}

Raymond F. Stainback, MD, Department of Adult Cardiology, Texas Heart Institute, 6624 Fannin St., Suite 2480, Houston, TX 77030

From: Rush Center for Congenital \& Structural Heart Disease, Rush University Medical Center, Chicago, Illinois 60612

Address for reprints: Zahid Amin, MD, Children's Hospital of Georgia, Georgia Regents University, Rm. BAA 8300, 1120 - 15th St

Augusta, GA 30912

E-mail: Zamin@gru.edu

(c) 2015 by the Texas Heart ${ }^{\circledR}$ Institute, Houston

\section{Ductus Arteriosus Aneurysm with Organized Thrombus in a Neonate:}

\author{
Echocardiograms from Diagnosis to Resolution
}

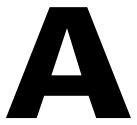

7.5-lb female neonate was delivered at term, by means of a caesarian section, to a 26-year-old mother (her 2nd pregnancy). The infant had good Apgar scores but was transferred to the neonatal intensive care unit because of respiratory distress. She was treated for transient tachypnea and for bilateral spontaneous pneumothoraces. She improved with minimal respiratory support. Transthoracic echocardiography (TTE) revealed an aneurysmal ductus arteriosus (DA) with a large thrombus (Fig. 1). The patient was observed clinically and was started on $40 \mathrm{mg} / \mathrm{d}$ of aspirin. When the infant was 3 weeks old, TTE showed that the DA lumen was almost completely obliterated by the thrombus (Fig. 2). Two weeks later, TTE revealed complete resolution of the DA aneurysm and no thrombus (Fig. 3). The aspirin therapy was discontinued.

\section{Comment}

Ductus arteriosus aneurysm is characterized by a localized saccular or tubular dilation of the DA. The DA aneurysm most likely develops during the 3rd trimester, and the typical age of diagnosis is early infancy. ${ }^{1}$ Reported sequelae include spontaneous rupture, erosion, thromboembolism, infection, and compression of adjacent structures. The reported incidence of thrombus formation is $30 \%$ to $37 \% .^{1,2}$ The probable causes of DA aneurysm include exposure of the ductal wall to systemic pressure, congenital weakening of the ductal wall, and abnormal intimal cushion formation and defective elastin. ${ }^{1,3}$ Although DA aneurysm can be associated with syndromes and connective tissue diseases, many affected infants experience a benign course.
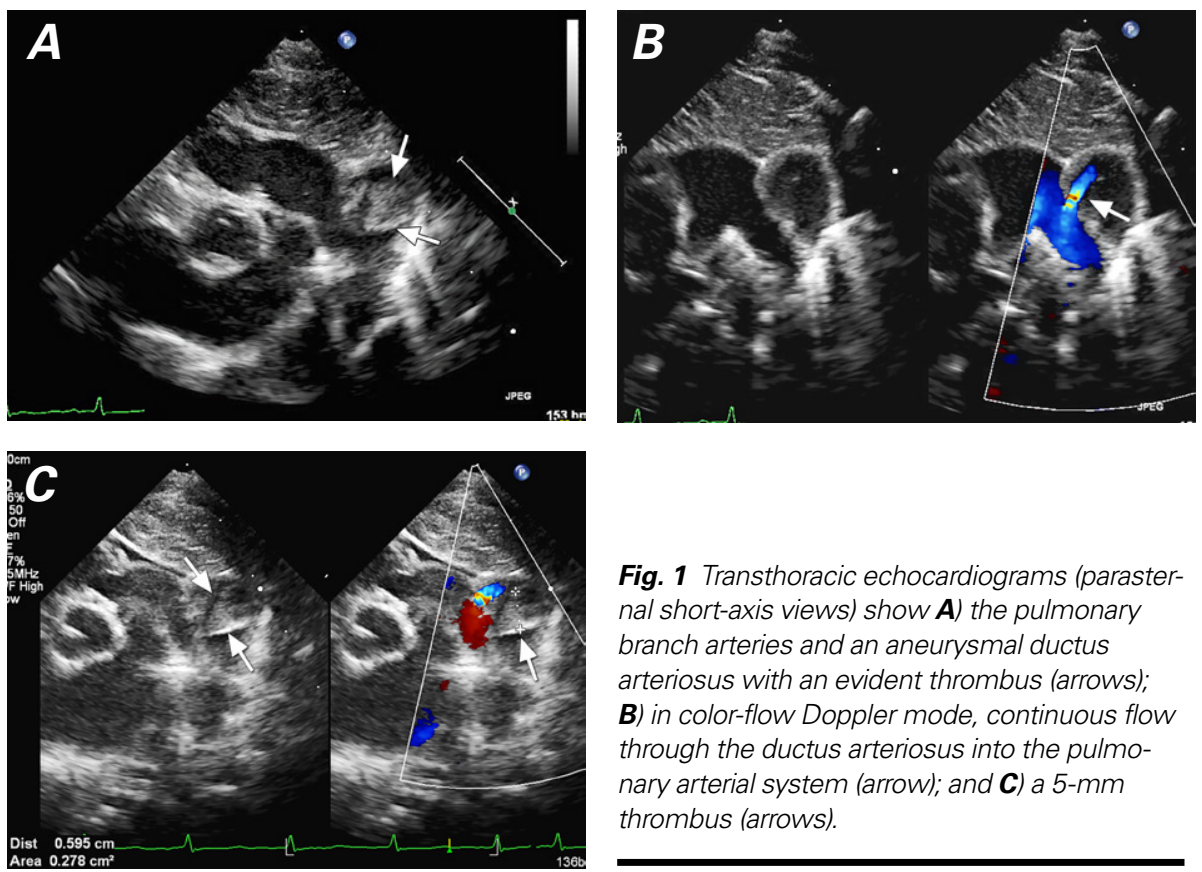

Fig. 1 Transthoracic echocardiograms (parasternal short-axis views) show $\boldsymbol{A}$ ) the pulmonary branch arteries and an aneurysmal ductus arteriosus with an evident thrombus (arrows); B) in color-flow Doppler mode, continuous flow through the ductus arteriosus into the pulmonary arterial system (arrow); and C) a 5-mm thrombus (arrows). 

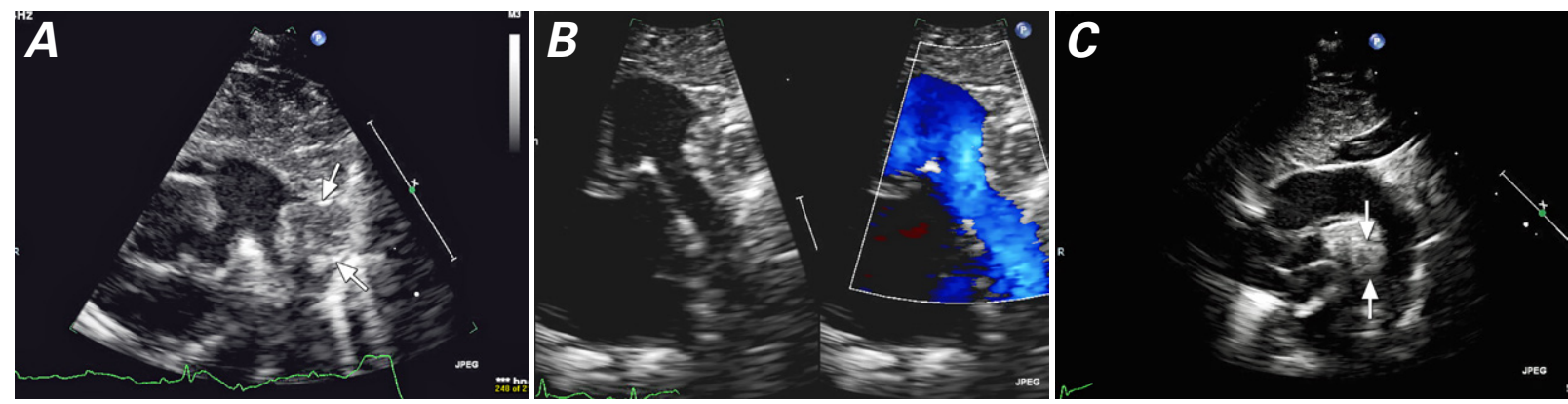

Fig. 2 Transthoracic echocardiograms. The parasternal short-axis views reveal $\boldsymbol{A}$ ) the organization of the thrombus and almost complete obliteration of the ductus arteriosus lumen, and $\boldsymbol{B}$ ) the absence of ductal flow, in color-flow Doppler mode. C) The suprasternal view shows the aortic arch and ductal thrombus.
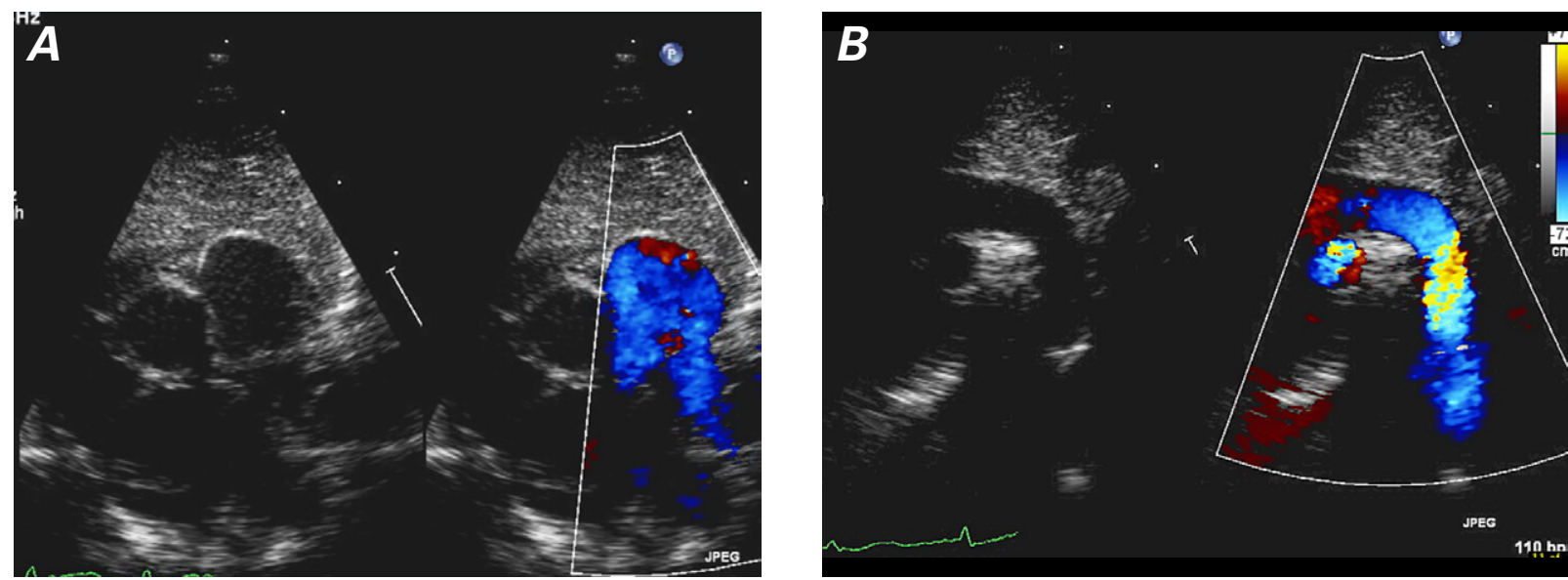

Fig. 3 Transthoracic echocardiograms. A) The parasternal short-axis view reveals confluent pulmonary branch arteries with unobstructed flow and complete resolution of the ductus arteriosus aneurysm and thrombus. B) The suprasternal view shows a patent aortic arch and no evident ductus arteriosus flow or thrombus.

\section{References}

1. Dyamenahalli U, Smallhorn JF, Geva T, Fouron JC, Cairns $\mathrm{P}$, Jutras L, et al. Isolated ductus arteriosus aneurysm in the fetus and infant: a multi-institutional experience. J Am Coll Cardiol 2000;36(1):262-9.

2. Jan SL, Hwang B, Fu YC, Chai JW, Chi CS. Isolated neonatal ductus arteriosus aneurysm. J Am Coll Cardiol 2002;39(2): 342-7.

3. Lund JT, Jensen MB, Hjelms E. Aneurysm of the ductus arteriosus. A review of the literature and the surgical implications. Eur J Cardiothorac Surg 1991;5(11):566-70. 